\title{
Construction and Design of a Modular Permanent Magnet Transverse Flux Generator
}

\author{
Ioan-Adrian VIOREL ${ }^{1}$, Larisa STRETE ${ }^{1}$, Kay HAMEYER ${ }^{2}$ \\ ${ }^{I}$ Technical University of Cluj-Napoca/Electrical Machines \\ ${ }^{2}$ Institute of Electrical Machines, RWTH Aachen, Germany \\ str. Daicoviciu nr.15, RO-400020 Cluj-Napoca \\ ioan.adrian.viorel@mae.utcluj.ro
}

\begin{abstract}
A simple construction of a modular transverse flux generator with permanent magnets in the rotor is proposed in the paper. The specific technology is detailed and an analytical design algorithm is developed. A simplified model is proposed for calculating the machine heating and three dimensions magnetic flux calculation via finite element method (FEM) is carried on in order to check the main generator characteristics.
\end{abstract}

Index Terms - electric machines, equivalent circuits, finite element methods, permanent magnet generator, thermal factors

\section{INTRODUCTION}

The transverse flux (TF) machine, which is similar to the claw pole alternator, has two important advantages, larger power density as compared to conventional machines, and a modular construction [1, 2, 3]. The TF machine has a complicated structure and large leakages due to its homopolar armature pattern, leading to a low power factor. Since the TF machine modularity is an advantage that does not occur in the case of conventional machines, a TF generator would be a very good solution for micro and mini stand alone electric power plants, if its construction would be less complicated, and consequently, the costs would be lower.

In this paper, the construction and the design procedure of a permanent magnet (PM) excited TF generator (PMTFG) of a simple structure, is presented.

An algorithm for the sizing-designing procedure is developed in the paper, and a simplified model to calculate the machine heating is proposed. Three-dimension finite element method (3D-FEM) analysis is carried on to calculate the main machine characteristics, as magnetizing and leakage fluxes and electromagnetic torques.

\section{PMTFG CONSTRUCTION}

The PMTFG structure proposed here comes from the usual TF reluctance machine with passive rotor and the only change is made in the rotor by providing it with PMs. The $\mathrm{TF}$ reluctance machine elemental structure, which stays as the basic for the actual PMTFG, is shown in Figure 1. It has an usual stator topology, the rotor pole piece being made out of steel laminations without PMs or coils of any type. The three dimensions (3D) view of the PMTFG one phase module is given in Figure 2.

The stator and the rotor poles of the PMTFG can be made out of steel sheets or soft magnetic composite (SMC) materials. SMC materials allow a 3D flux pattern since they have the same magnetic properties in all directions. Usually, the rotor poles of the proposed PMTFG should be made out of SMC, but the stator core can also be made of SMC, due to the less complicated construction technology. The stator core must be made for each pole pair of two separate parts, in order to facilitate the machine manufacturing technology, even if this will lead to an extra air-gap.

The stator and rotor case must be provided with special holes where the pole pieces will be introduced to ease the machine assemblage and to consolidate the whole structure.

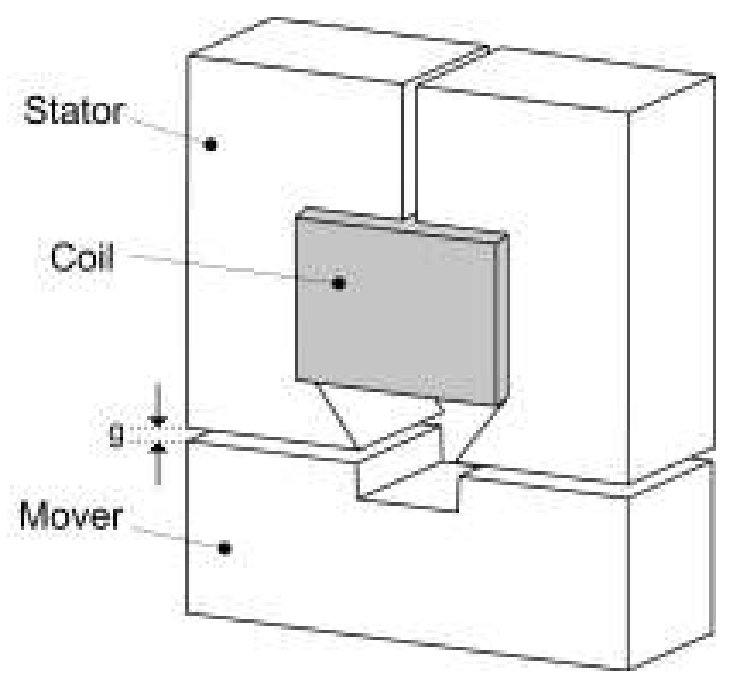

Figure 1. A basic structure of a TF reluctance machine.

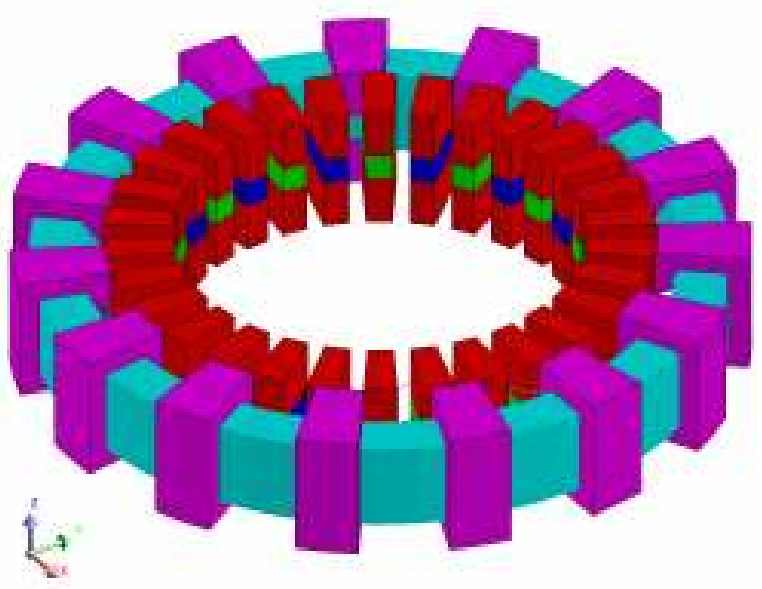

Figure 2. 3D view of the PMTFG phase module. 
The proposed PMTFG can have one or multiple phases, and several modules connected in parallel. This is an important advantage for large production case, since a wide range of power can be covered for the stand-alone plants. It has to be mentioned that the stand-alone plants must have an $\mathrm{AC} / \mathrm{DC} / \mathrm{AC}$ converter and an energy storage device, like a bulk of lead acid batteries, for example.

\section{PMTFG DESIGN PROCEDURE}

Basically, an electric machine designing procedure must follow four compulsory steps:

1) Sizing-designing step, when the main dimensions and characteristics are estimated;

2) $\mathrm{A} 2 \mathrm{D}$ or $3 \mathrm{D}$ - FEM analysis to check the electromagnetic performances of the previously calculated machine;

3) Loss and heating calculation via $2 \mathrm{D}$ or $3 \mathrm{D}-\mathrm{FEM}$, or other accurate method;

4) Computer simulation of the machine behavior embedded with its driving system.

Within this paper, the specific sizing-designing procedure of the proposed PMTFG is presented, extra attention being paid to the PM magnetization and leakage flux calculation via equivalent magnetic circuits. The $3 \mathrm{D}$ finite element method (FEM) is employed to check the accuracy of the results obtained via the sizing-designing procedure.

The thermal analysis of the PMTFG is conducted by using a thermal equivalent circuit and the following simplifying assumptions are considered: the heat transfer through radiation is null and the machine body consists of homogenous parts, as far as the heating-cooling process is concerned.

Since all the PMTFG parameters are calculated within the sizing-designing procedure and some of them are also checked via 3D-FEM analysis, the computer simulation of the entire stand-alone power plant can be easily performed, once its structure is defined, but this was not an objective of the paper.

\section{PMTFG SizING DESIGNING}

Within the sizing process, the air-gap diameter is calculated as function of design specifications, some sizing factors and the machine magnetic and electric loadings $[1,2$, $3,4,5,6,7]$. The detailed general procedure is presented in $[2,3,4,8,9,10]$. Specific aspects of the sizing-designing procedure for the given PMTFG structure are discussed in [11] and extended in the present paper, where different magnetic equivalent circuits are considered in order to calculate the fluxes, with or without current in the armature winding.

When no current is supplied to the armature winding, the no load-operating regime, two consecutive rotor pole pairs are to be considered, Figure 3, in order to evince the side-toside leakage flux $\Phi_{\sigma s s}$, which flows from one rotor pole to the neighboring pole, Figure 4.

One rotor pole pair is in aligned position, pole pair number 1 , the other one considered being adequately shifted. For each rotor pole pair, the PM leakage flux $\left(\Phi_{\sigma P M}\right)$ and the main flux $\left(\Phi_{P M}\right)$, are considered. The air-gap flux $\left(\Phi_{0 g}\right)$ and the resulting flux trough stator core $\left(\Phi_{O S}\right)$ are adequately correlated. The notations for the magnetic reluctances are the usual ones: $R_{P M}$ is the PM reluctance, $R_{\sigma P M}$ and $R_{\sigma s s}$ are the leakage reluctances, while $R_{g 1}, R_{g 2}$ are the air-gap reluctances calculated for two rotor pole pieces (the aligned one and the shifted one, respectively).

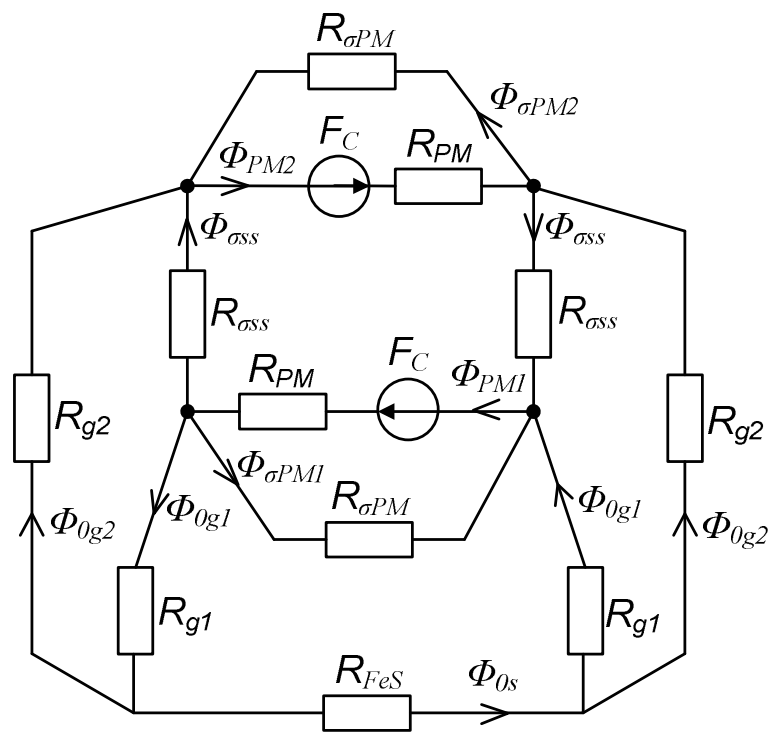

Figure 3. Magnetic equivalent circuit at no load $(I=0)$

The PMs own leakage fluxes composed of side leakage flux $\Phi_{\sigma s}$, air-gap flux $\Phi_{\sigma g}$, bottom leakage flux $\Phi_{\sigma b}$ and respectively the side to side leakage flux $\Phi_{\sigma s s}$, are evinced in Figs. 4 and 5.

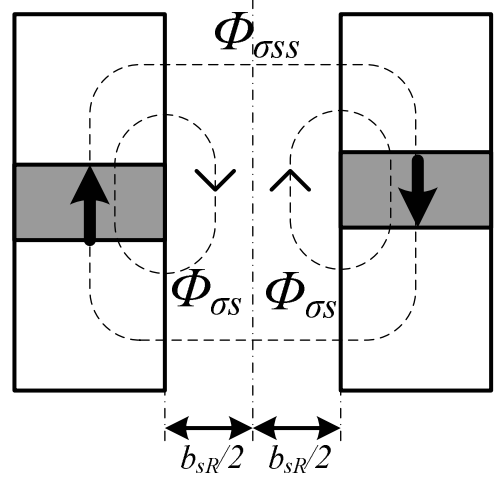

Figure 4. Rotor pole, side and side-to-side leakage flux.

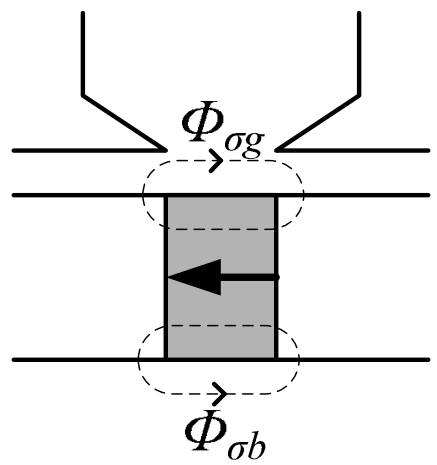

Figure 5. Rotor PM air-gap and bottom leakage flux.

The considered leakage fluxes of one PM are substituted by an equivalent flux, the reluctance equivalence being given in equation (1).

$\frac{1}{R_{\sigma P M}}=\frac{1}{R_{\sigma g}}+\frac{1}{R_{\sigma s}}+\frac{1}{R_{\sigma b}}$ 
The magnetic equivalent circuit given in Fig. 3, for zero armature current, does not contain a magnetic reluctance corresponding to the rotor pole, but it can be introduced, and the core nonlinearity can also be taken into consideration.

The armature reaction fluxes are calculated in aligned, $\Phi_{S g a}$ and un-aligned rotor position, $\Phi_{S g u n}$, the fluxes ratio being considered equal to the main inductances ratio:

$\Phi_{S g a} / \Phi_{\text {Sgun }}=M_{d} / M_{q}$

Equation (2) allows for an easy calculation of the q-axis inductance, once $M_{d}$ is obtained.

In order to avoid the PM demagnetization process, the airgap flux produced by PM in aligned rotor position must be greater than the air-gap flux produced by stator $\mathbf{m m f}$ in the same rotor position,

$\Phi_{0 g a}>\Phi_{S g a}$

From (3) results a condition for the minimum PM length to avoid the demagnetization, once all other dimensions are given.

Supposing that the resulting air-gap flux density varies sinusoidal, the peak value of the cogging torque can be approximated by:

$T_{c g}=Q_{S}^{2} \frac{g \cdot B_{g \max }^{2}}{\mu_{0}}$

where $Q_{S}$ is the number of stator pole pieces, $g$ is the actual air-gap length and $B_{\text {gmax }}$ is the peak value of the air-gap flux density.

\section{PMTFG THERMAL MODEL}

Thermal modeling is a very important stage in the design process of electrical machines, whether they are rated continuously or subject to sparse duty-cycle operation.

Different analytical methods can be applied for computing the heat transfer of electrical machines. All methods employed are based on the assumption that the machine can be divided in homogenous regions regarding the heating/cooling process.

The heat transfer between different parts of the machine or from machine to exterior takes place through conduction or convection, the radiation being small enough to be neglected. Thermal circuit models, similar to the electrical circuits or magnetic equivalent circuits, are used in PMTFG thermal modeling, Figure 6.

The following thermal resistances are calculated for the stator and rotor thermal model:

$R_{t C u F e}$ - thermal resistance from coil to the stator iron core

$R_{t F e S}$ - thermal resistance at the stator pole base

$R_{t S a}$ - thermal resistance from stator iron core to exterior

$R_{t g S}$ - thermal resistance in air-gap

$R_{t F e R}$ - thermal resistance in the stator iron core

$R_{t R a}$ - thermal resistance from rotor iron core to exterior

$R_{t g R}$ - thermal resistance from rotor to air-gap

$R_{t F e S}^{\prime}$ - modified thermal resistance in the stator iron core
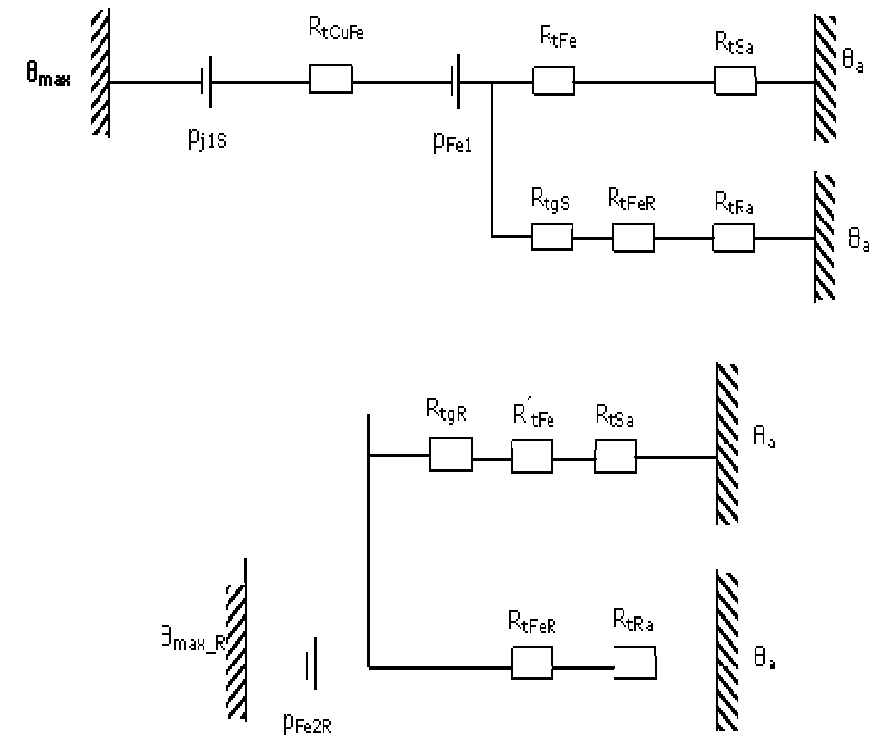

Figure 6. PMTFG thermal equivalent circuits a) heat transfer from stator to rotor and exterior b) heat transfer from rotor to stator and air-gap.

The total thermal resistance, when considering only the stator model, is:

$R_{t e S}=R_{t C u F e}+\frac{\left(R_{t F e S}+R_{t S a}\right) \cdot\left(R_{t g S}+R_{t F e R}+R_{t R a}\right)}{R_{t F e S}+R_{t S a}+R_{t g S}+R_{t F e R}+R_{t R a}}$

The total rotor thermal resistance becomes:

$R_{t e R}=\frac{\left(R_{t F e R}+R_{t R a}\right) \cdot\left(R_{t g R}+R_{t F e S}^{\prime}+R_{t S a}\right)}{R_{F e R}+R_{t R a}+R_{t g R}+R_{t F e S}^{\prime}+R_{t s a}}$

The temperature rise, when considering both stator and rotor losses, is:

$\Delta \theta_{\max }=\left(p_{j S}+p P_{F e S}\right) \cdot R_{t e S}+\left(p_{F e R}\right) \cdot R_{t e R}$

where $p_{j S}$ and $p_{F e R}$ are the stator copper and iron losses and, respectively, the rotor iron losses calculated for one stator and two rotor pole pieces.

\section{3D-FEM CALCULATION}

The 3D-FEM analysis is employed in order to check the analytical results obtained via the sizing designing procedure and to obtain a suboptimal PMTFG variant, by reducing the leakage fluxes, and increasing the magnetizing flux.

Due to the machine symmetry, when performing the 3DFEM analysis, the 3D-PMTFG structure contains two rotor and one stator pole pieces, as shown in Figure 7. They were modeled in a manner that allows automatic re-meshing at different rotor positions. A 3D-FEM package from CEDRAT (Flux 3D) was employed.

In order to further analyze the rotor PM leakage and main fluxes, two support planes were constructed in the model, at midway between two neighboring rotor pole pieces, in the radial axis of the PM and in the middle of the air-gap. Taking advantage of such an extended 3D-FEM model, different rotor poles topologies can be studied, looking for the smallest leakage fluxes and the largest magnetizing flux for a given PM volume. 


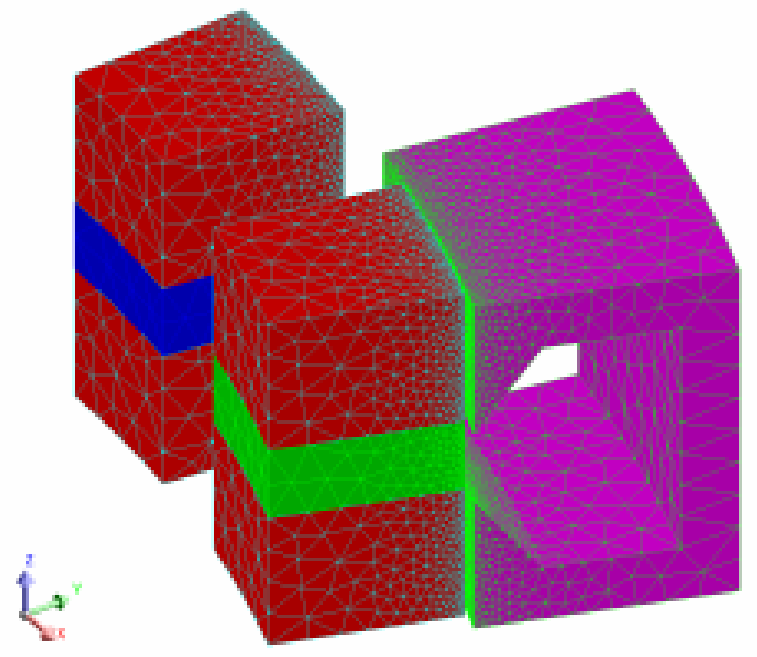

Figure 7. PMTF machine meshing.

\section{CAlculated Results}

To avoid the problems that can appear if the number of mesh elements is too large and to obtain accurate results via $3 \mathrm{D}-\mathrm{FEM}$ analysis, a relatively small size and power PMTF machine was considered $(1.2 \mathrm{~kW}$ at $300 \mathrm{rpm})$. In Table I, the comparison between analytical and 3D-FEM analysis calculated values of the fluxes is given.

\begin{tabular}{|c|c|c|c|c|c|}
\hline & $\Phi_{P M I}$ & $\Phi_{0 g l}$ & $\Phi_{P M 2}$ & $\Phi_{0 g 2}$ & $\Phi_{\sigma s s}$ \\
\hline Analytical & 2.3 & 1.3 & 1.6 & 0.6 & 0.9 \\
\hline 3D-FEM & 2.0 & 1.1 & 1.7 & 0.7 & 0.7 \\
\hline
\end{tabular}

The differences look impressive, mainly in the case of $\Phi_{\sigma s s}$, but separating this one from the other leakages of the $\mathrm{PMs}$ is quite difficult, and the 3D-FEM results might also contain small errors. In fact, one can see that for 3D-FEM results, the difference between $\Phi_{0 g}+\Phi_{\sigma s s}$ and $\Phi_{P M}$ is larger for both rotor pole pieces than the same values calculated via the magnetic equivalent circuit.

For the same machine and topology, the peak cogging torque values are $7.4 \mathrm{Nm}$ and $6.4 \mathrm{Nm}$ respectively, calculated analytically and by employing the 3D-FEM analysis, Figure 8.

To obtain the results given in Fig. 8, three cases were considered:

i) The variable reluctance machine when the PM volume was substituted by magnetic material

ii) The PMTFG at no load $I=0$, to evince the cogging torque

iii) The PMTFG operating at rated current

As one can see, the reluctance torque, case $i$ ) is favorable, since it reduces the cogging torque.

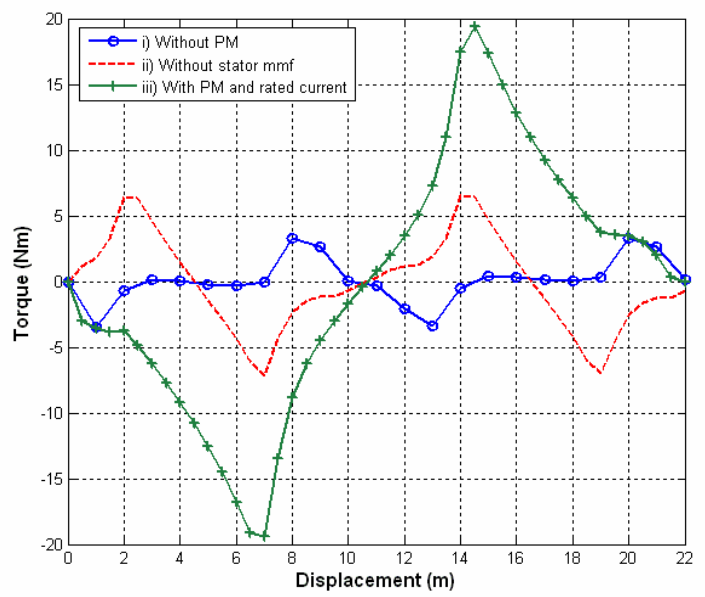

Figure 8. PMTFG torque per module versus rotor displacement.

\section{CONCLUSIONS}

The construction and the design procedure for a simple modular PMTFG are presented, and some technological details are discussed. The sizing-designing algorithm is developed and it is only briefly presented in the paper. The thermal and the 3D-FEM models are introduced and some comparative results are given.

As an overall conclusion, it can be pointed out the fact that the models and the sizing-designing procedure are accurate enough, and that they can be easily extended to other similar machines.

\section{REFERENCES}

[1] H. Weh., J. Jiang, "Berechnungsgrundlagen für Transversalflussmaschinen" Archiv f. Electrotechinik, vol 71, 1988, pp. 187-198.

[2] I.-A. Viorel, G. Henneberger, R. Blissenbach, L. Löwenstein: „Transverse flux machines. Their behavior, design, control and applications“", Mediamira Publishing House, Cluj, Romania, 2003.

[3] G. Henneberger, I.-A.,Viorel, Variable reluctance electrical machines. Shaker Verlag, Aachen, Germany, 2001.

[4] I. Boldea, "Variable speed generators", Taylor and Francis, 2005.

[5] M. R. Dubois, "Optimized permanent magnet generator topologies for direct-drive wind turbines", PhD. Thesis, Technical University of Delft, Holland, 2004

[6] V. B. Hosinger, "Sizing equations for electrical machinery", IEEE Trans on EC, vol.2, no.1, pp.116-121, 1987.

[7] S. Huang, J. Luo, F. Leonardi, T. A. Lipo, "A comparison of power density for axial flux machiens based on general purpose sizing equations", IEEE Trans on EC, vol.14, no.2, pp.185-192, 1999.

[8] R. Blissenbach, I.-A. Viorel, G. Henneberger, "On the single sided transverse flux machine design", Electric Power Components and Systems, vol. 31, no.2, pp 109-128, 2003.

[9] P. Anpalahan, "Design of transverse flux machines using analytical calculations and finite element analysis", Master Thesis, Royal Institute of Technology, Stockholm, 2001.

[10] W. M. Arshad, T.Backstrom, C. Sadarangari,.:"Analytical design and analysis procedure for a transverse flux machine", Proc of IEMDC'01, Cambridge, MA, USA, pp. 115-121, 2001.

[11] Larisa Strete, I.-A. Viorel, Alina Viorel, "On the designing procedure of a permanent magnet transverse flux generator (PMTFG) with specific topology" in Proc. of OPTIM'08, Brasov, Romania, vol 2-A, pp. 99-104. 